\title{
GROUP ACTIVITY PARTICIPATION IN RELATION TO CONTEXTUAL ISOLATION OF UNITED STATES NURSING HOME RESIDENTS LIVING WITH ALZHEIMER'S DISEASE AND RELATED DEMENTIAS
}

\author{
B.M. JESDALE ${ }^{1}$, C.A. BOVA², A.K. MBRAH ${ }^{1}$, K.L. LAPANE ${ }^{1}$ \\ 1. Division of Epidemiology, Department of Population and Quantitative Health Sciences, University of Massachusetts Medical School, Worcester, MA, USA; 2. Graduate School of \\ Nursing, University of Massachusetts Medical School, Worcester, MA, USA. Corresponding author: Kate Lapane, PhD, University of Massachusetts Medical School, 55 Lake Avenue \\ North, Worcester, MA 01605, USA, Telephone number: 508-856-8798, Fax: 508-856-8993, Email: Kate.lapane@ umassmed.edu
}

\begin{abstract}
Background: Residents of nursing homes frequently report loneliness and isolation, despite being in an environment shared with other residents and staff. Objective: To describe, among long-stay US nursing home residents living with Alzheimer's disease and/or related dementias (ADRD), group activity participation in relation to contextual isolation: living in a nursing home where fewer than $20 \%$ of residents share socially salient characteristic(s). Design: A cross-sectional evaluation of group activity participation in relation to contextual isolation across 20 characteristics based on demographic characteristics, habits and interests, and clinical and care dimensions. Setting: US nursing homes. Participants: We included 335,421 residents with ADRD aged $\geq 50$ years with a Minimum Data Set 3.0 annual assessment in 2016 reporting their preference for group activity participation, and 94,735 with participation observed by staff. Measurements: We identified 827,823 annual (any anniversary) assessments performed on nursing home residents in 2016, selecting one at random for each resident, after prioritizing the assessment with the least missing data $(n=795,038)$. MDS 3.0 item F0500e assesses resident interest in group activities. Results: When considering all potential sources of contextual isolation considered, $30.7 \%$ were contextually isolated on the basis of a single characteristic and $13.7 \%$ were contextually isolated on the basis of two or more characteristics. Among residents reporting importance of group activity, $81 \%$ of those not contextually isolated reported that group activity participation was important, as did $78 \%$ of those isolated on one characteristic, and $75 \%$ of those isolated on multiple characteristics. Among residents with staffobserved group activity participation, $64 \%$ of those not contextually isolated reported were observed participating in group activities, as were $59 \%$ of those isolated on one characteristic, and $52 \%$ of those isolated on multiple characteristics. Conclusion: Residents with ADRD facing contextual isolation placed less importance on group activity than residents who were not contextually isolated.
\end{abstract}

Key words: Nursing homes, social isolation, Alzheimer's disease, dementia.

Abbreviations: ADRD: Alzheimer's Disease and related dementias; HIV: Human immunodeficiency viru; MDS: Minimum Data Set.

\section{Introduction}

Residents of nursing homes frequently report loneliness and isolation, despite being in an environment shared with other residents and staff. Adjusting to life in both a home and care setting can be an isolating experience $(12,21)$. In addition to being unpleasant in its own right, isolation has long been understood to contribute to worsening health conditions and accelerated time to death $(9,10,15,16)$.

Residents with Alzheimer's Disease and related dementias (ADRD) may be particularly likely to experience social isolation in nursing homes due to the nature of cognitive impairment, along with other factors (24). They often spend prolonged periods in a nursing home, with half living in this setting for more than two years, and many living out the remainder of their lives there $(27,29)$.

The great majority of nursing homes offer group activities, including weekend activities (98\% of nursing homes), evening activities (95\%), outdoor activities (95\%), and intergenerational activities (85\%) (20). Although cognitively impaired residents

Received April 23, 2021

Accepted for publication July 26, 2021 with dementia are more likely to decline to participate in group activities, those who do engage in longer stretches of activity (7). Activity therapists can play a large role in the degree to which residents feel welcomed and included in group activities, perhaps especially for residents at risk of exclusion due to being in a minority of residents (3). Techniques such as modeling activities and small group settings can improve participation in group activities, particularly for residents with severe cognitive impairment $(8,25)$. Group activities are particularly important tools for reducing loneliness and boredom of residents with dementia $(1,5)$, and social stimuli decrease behavioral symptoms and improve affect in these residents (6).

In this study, we first introduce the concept of "contextual isolation" in nursing homes - namely, the condition of 1) possessing a socially salient characteristic, and 2) being in a context where few other residents share that characteristic. We consider residents in a situation where they are contextually isolated on one or more characteristics to be at risk of the experience of isolation, although not determinative of 


\section{THE JOURNAL OF NURSING HOME RESEARCH SCIENCESC}

an individual's experience of isolation. For example, being the only Spanish speaking resident in a setting where the residents and staff speak only English may place them at risk of social isolation. We propose potential measures of contextual isolation, based on demographic characteristics (young age, gender, marital status, race/ethnicity, staff needs translator services to communicate with resident, heavy-bodied), habits and interests (tobacco use, importance of religious practice, importance of music, importance of pets, importance of keeping up with the news), and clinical diagnoses and care dimensions (active cancer, human immunodeficiency virus (HIV) infection, intellectual disability, sensory deprivation, disfiguring conditions (amputation, paralysis, burns), stroke, and physiciandocumented limited life expectancy). Second, we sought to validate the concept against measures of resident group activity participation. We hypothesized that contextual isolation would be a common phenomenon experienced by nursing home residents with ADRD; and that contextually isolated residents would express less interest in engaging in group activities than residents who are not contextually isolated, even among residents sharing the same socially salient characteristics who are not contextually isolated.

\section{Methods}

The University of Massachusetts Medical School Institutional Review Board approved this study. The nurse expert survey was work conducted preparatory to research.

\section{Data Source}

We used resident-level and facility-level aggregated data from resident assessments completed using the Minimum Data Set 3.0 (MDS) instrument (4). MDS assessments are required of all residents of Medicare and Medicaid supported nursing homes in the US and US territories, at admission, quarterly thereafter, and when there is a significant change in clinical status. The Minimum Data Set 3.0 assessment is a collaborative document: residents are interviewed for substantial portions of the assessment, and multiple direct care staff contribute to the assessment. Completion of the document is typically overseen by a nurse coordinator responsible for ensuring that all relevant assessments are conducted according to detailed guidance documents (4). All measures to develop contextual isolation measures were derived from standard MDS 3.0 items.

\section{Long-Stay Population}

We identified 827,823 annual (any anniversary) assessments performed on nursing home residents in 2016. For each resident, we selected one at random, after prioritizing the assessment with the least missing data $(\mathrm{n}=795,038)$ (Figure 1). Among these long-stay residents, 456,771 had a diagnosis of Alzheimer's disease (MDS item I4200) and/or other dementia (I4800). We excluded residents who were aged less than 50 years (or had unknown age) $(n=467)$, were comatose (or unknown) at the time of assessment $(n=308)$, had missing information on any variable needed to assess contextual isolation (described in detail below) $(\mathrm{n}=25,149)$, lived in a nursing home with fewer than 10 residents $(\mathrm{n}=17)$, or did not have a valid assessment of group activity participation $(n=674)$, resulting in a final sample of 430,156 residents.

Figure 1

Sample Construction

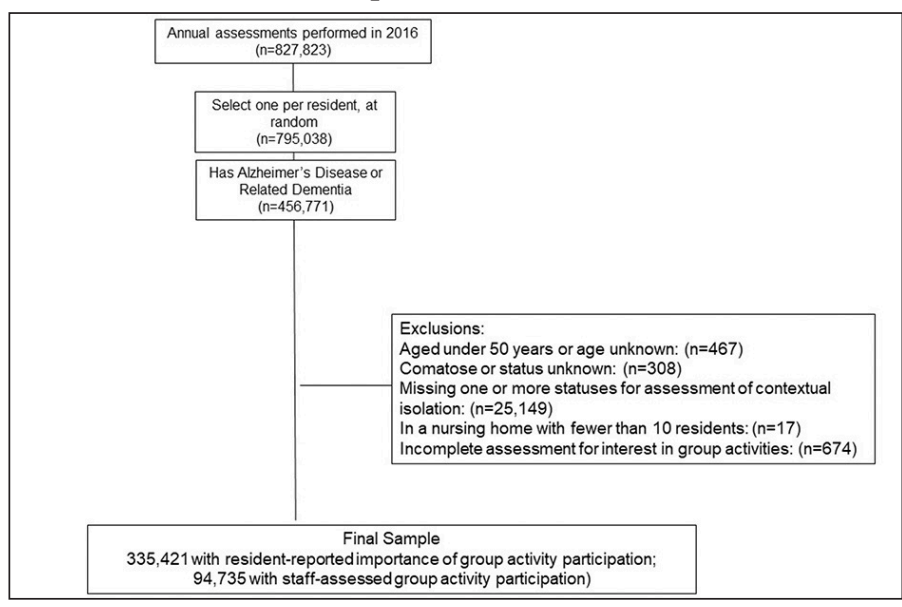

\section{Contextual Isolation}

We developed an expansive list of socially salient characteristics that we felt could potentially be the basis for contextual isolation in the nursing home setting, regardless of whether these characteristics could be readily measured in our dataset (see Supplemental Table 1). We then solicited feedback from seven experts (selected by C.A.B) in nursing home care on three aspects we conceived of as most relevant to the concept of contextual isolation: 1) how often is this characteristic a source of shared experiences / solidarity with other residents; 2) how often is this characteristic a basis for potential exclusion / ostracism by other residents; and 3) how often this characteristic contributes to a sense of identity within the nursing home. We offered four response options (for all or almost all residents with this characteristic (score $=4$ ), for most residents with this characteristic (score $=3$ ), for some residents with this characteristic(score $=2$ ), for no or very few residents with this characteristic (score $=1$ ). Scores for each characteristic were averaged. We also solicited written comments and narratives to further characterize these nurse experts' opinions. Supplemental Table 2 summarizes the expert opinions. We applied the following criteria to each characteristic to be further considered in our development of contextual isolation: 1) readily measurable using MDS 3.0 data; 2) average score of $>=2$ on the "shared experience" item; 3 ) average score of $>=2$ on the "sense of identity" item. We did not rely on the "social exclusion" item after review of nurse expert opinions and comments, because this item did not conceptually fit with the narratives that our nurse experts described. Because the narratives and comments of our nurse experts described 


\section{CONTEXTUAL SOCIAL ISOLATION}

advanced age as a source of reverence by out-group members, as opposed to in-group solidarity, we did not include this among the contextual isolation measures. Shaded rows in Supplemental Table 2 indicate the social characteristics not considered further. The characteristics excluded because the MDS 3.0 lacked measures were: being lesbian, gay or bisexual, having children, veteran status, and shared political orientation. We excluded being transgender (based on Section I diagnosis codes) because fewer than 10 residents in our long-stay sample with ADRD met this criterion.

Operational details of the included social characteristics are provided in Supplemental Table 3. We created quarter-specific $(1 / 1-3 / 31,4 / 1-6 / 30,7 / 1-9 / 30,10 / 1-12 / 31)$ tabulations of residents within each nursing home for the above characteristics, drawing on both short-stay and longterm residents, regardless of eligibility for our long-stay analytic sample described above. For residents with multiple assessments in a given quarter, we selected one assessment at random, after prioritizing the assessments with the most complete data. Additionally, because some items are not included in quarterly assessments, we carried the most recent non-missing value forward (no more than 300 days to capture the most recent comprehensive assessment) to substitute for missing values to more accurately characterize the pool of residents in each nursing home residence. Among nursing homes with at least 10 residents, we calculated the proportion of residents sharing each of the selected social characteristics.

To identify which residents in our long-term cohort living in nursing homes were contextually isolated, we identified those with a given social characteristic also living in a nursing home with fewer than $20 \%$ of residents possessing the same social characteristic. We also created summary measures that categorized residents as contextually isolated on no, one, or two or more of these characteristics. In sensitivity analyses, we conducted a parallel analysis using different thresholds based on expert opinions.

\section{Participation in Group Activities}

MDS 3.0 item F0500e assesses resident interest in group activities by soliciting from the resident and/or a relative or close friend involved in their care: "While you are in this facility...how important is it to you to do things with groups of people?", with possible responses of "Very important", "Somewhat important", "Not very important", "Not at all important", and "Important, but can't do or no choice". Testretest reliability of this item was found to be high (17), as is agreement between residents and family proxies (14). For residents who had been judged to be unable to communicate and for whom no family was available to interview, or who were otherwise unable to answer this item, staff reported whether the resident had been observed engaging in group activities (yes/no) (F0800p).

\section{Analytic Approach}

In this descriptive paper, we did not employ modeling techniques. Rather, we focused on describing the proportion of residents with ADRD who experienced contextual isolation in relation to each of the social characteristics considered, the proportion experiencing contextual isolation in relation to any one of the social characteristics, and the proportion experiencing contextual isolation in relation to more than one of the included social characteristics. As a first step to validate the concept of contextual isolation as measured, we estimated the proportion of nursing home residents with ADRD who expressed different levels of interest in group activity participation across levels of contextual isolation. Because the self- and staff- reported group activity participation variables measure somewhat different concepts (importance of versus observed engagement in group activities), are reported from different sources (residents and/or family vs. staff), and are not concurrently reported for the same residents, we analyzed these populations separately throughout. There were 335,421 residents with an assessment of the importance of group activity participation as reported by the resident themselves or a proxy, and 94,735 with a valid staff report of being observed as participating in group activities or not.

Finally, because residents possessing a given socially salient characteristic may, as a population, have different levels of engagement in group activities, we also examined each of the socially salient characteristics used to define contextual isolation, and their complements. For example, although only "young age" was used to construct contextual isolation, we also examined additional age groups $(65-74,75$ to 84,85 to 94 , and $\geq 95$ years). In large samples, $p$-values are uninformative because trivial differences are often statistically significant; we a priori decided to treat absolute percentage differences of $5 \%$ or more to be notable, where the numerator of both percentages is greater than 50 .

\section{Suppression of Data Reporting}

While the Centers for Medicare and Medicaid Services requires the suppression of reporting any cell with fewer than 10 residents, we elected to suppress the display of proportions with a numerator of 50 or smaller, to avoid drawing inferences based on imprecise estimates.

\section{Results}

Among 335,421 long-stay residents with ADRD who were asked directly (or via family proxy) about the importance they place on participation in group activities, Table 1 describes the proportion with each of the social characteristics considered, and the proportion of residents contextually isolated on that basis. For example, $29.3 \%$ of the eligible long-stay residents with ADRD were male, and $1.6 \%$ of male residents lived in a nursing home where fewer than $20 \%$ of all residents (short-stay and long-stay, with or without ADRD) were also male, while 


\section{THE JOURNAL OF NURSING HOME RESEARCH SCIENCESC}

$70.7 \%$ of eligible residents were female, of whom $0.2 \%$ lived in a nursing home where fewer than $20 \%$ of residents were also female. Among the most contextually isolated residents among the groups we considered were those who were young (35.2\%), Hispanic (42.2\%), American Indian / Alaska Native $(66.2 \%)$, Asian (45.3\%), Pacific islander (78.2\%), multiracial $(100 \%)$, staff required a translator to communicate with the resident $(44.4 \%)$, current tobacco users $(64.6 \%)$, residents with an intellectual disability $(88.9 \%)$, a sensory impairment $(59.8 \%)$, a disfiguring condition $(84.7 \%)$, stroke $(61.2 \%)$, cancer $(95.6 \%)$, HIV infection $(78.4 \%)$, and those in end-of-life care $(94.3 \%)$. Conversely, contextual isolation was infrequent (under $5 \%$ of residents) on the basis of sex, being widowed, being White, not being a current tobacco user, engaging in religious practices, listening to music, engaging with animals, or keeping up with current events. Supplemental Table 4 describes comparable information for the 94,735 residents with no reported importance of group participation, but whose participation in group activities was observed by staff.

When considering all potential sources of contextual isolation, $30.7 \%$ were contextually isolated on the basis of a single characteristic, and $13.7 \%$ were contextually isolated on the basis of two or more characteristics (Table 2). Furthermore, the degree of contextual isolation on any basis (cumulative contextual isolation) varied substantially across resident strata. For example, although only $1.6 \%$ of men lived in a nursing home where fewer than $20 \%$ of co-residents were also men, more than half lived in a nursing home where they were contextually isolated with respect to at least one of the social characteristics we investigated, and nearly 1 in 5 were contextually isolated with respect to multiple social characteristics; at the same time, only $11.2 \%$ of women lived in nursing homes where they were contextually isolated with respect to multiple social characteristics. Supplemental Table 5 describes comparable information for the residents whose group activity participation was observed by staff.

Table 3 shows, among long-stay residents with ADRD, that men who lived in a nursing home with at least $20 \%$ male residents, $73.2 \%$ rated participation in group activities as important, while among men who were contextually isolated in relation to other male residents, $74.9 \%$ rated participation in group activities as important. Likewise, differences between residents who were or were not contextually isolated were small (under 5\%) for most characteristics, with the exception of residents who were Asian (85.5\% vs. 81.1\%), residents for whom staff required a translator to communicate $(86.0 \%$ vs. $80.6 \%)$, residents for whom participation in religious activities is important $(85.0 \%$ vs. $74.1 \%)$, residents for whom keeping up with the news is important $(82.0 \%$ vs. $73.3 \%)$, and residents living with HIV infection (88.2\% vs. 82.9\%). Supplemental Table 6 describes comparable information for the residents whose group activity participation was observed by staff.
Table 1

Contextual Isolation on the Basis of Individual Characteristics among Long-Stay US Nursing Home Residents in 2016 with Alzheimer's Disease and Related Dementias and Reported Importance of Group Activity Participation

\begin{tabular}{|c|c|c|}
\hline Social Characteristic & $\begin{array}{c}\text { Proportion } \\
\text { of Residents } \\
\text { with this } \\
\text { Characteristic } \\
(\mathbf{n}=\mathbf{3 3 5 , 4 2 1}) \\
\%\end{array}$ & $\begin{array}{c}\text { Contextual } \\
\text { Isolation on this } \\
\text { Characteristic } \\
\text { (Fewer than 20\% } \\
\text { of Co-Residents } \\
\text { Share this } \\
\text { Characteristic) } \\
\%\end{array}$ \\
\hline Male & 29.3 & 1.6 \\
\hline Female & 70.7 & 0.2 \\
\hline Married & 18.3 & 21.4 \\
\hline Widowed & 51.7 & 2.6 \\
\hline Never Married, Divorced or Separated & 30.0 & 8.7 \\
\hline Young age (50-64 years) & 6.5 & 35.2 \\
\hline Hispanic, of any race(s) & 5.8 & 42.2 \\
\hline \multicolumn{3}{|l|}{ Not Hispanic and } \\
\hline White only & 77.6 & 0.6 \\
\hline Black only & 14.2 & 25.6 \\
\hline American Indian / Alaska Native only & 0.3 & 66.2 \\
\hline Asian only & 1.8 & 45.3 \\
\hline Native Hawaiian or other Pacific Islander only & 0.3 & 78.2 \\
\hline Multiracial & $<0.1$ & 100.0 \\
\hline Staff needs translator & 5.7 & 44.4 \\
\hline Heavy-bodied (BMI 30-60 kg/m²) & 26.8 & 5.8 \\
\hline Current tobacco use & 4.2 & 64.6 \\
\hline No current tobacco use & 95.8 & $<0.1$ \\
\hline Religious practices important & 79.9 & $<0.1$ \\
\hline Religious practices not important & 20.1 & 16.3 \\
\hline Music important & 89.2 & $<0.1$ \\
\hline Pets/animals important & 64.1 & 0.8 \\
\hline News/current events important & 72.7 & $<0.1$ \\
\hline Intellectual disability & 1.9 & 88.9 \\
\hline Sensory impairment & 16.7 & 59.8 \\
\hline Disfiguring condition & 9.2 & 84.7 \\
\hline Stroke & 11.0 & 61.2 \\
\hline Cancer & 5.0 & 95.6 \\
\hline HIV infection & 0.2 & 78.4 \\
\hline End of life care & 2.0 & 94.3 \\
\hline
\end{tabular}

Table 4 demonstrates that $80.6 \%$ of residents not contextually isolated on any basis rated participation in group activities as important, while $77.6 \%$ of residents contextually isolated on the basis of a single characteristic did, and $75.2 \%$ of residents experiencing contextual isolation on the basis of multiple characteristics did. Rating participation in group activities as important varied dramatically across resident strata. For example, among residents who were not contextually isolated on any social characteristics, $85.6 \%$ of residents who engage in religious practices rated group participation as important, while $55.7 \%$ of comparably situated residents who 


\section{CONTEXTUAL SOCIAL ISOLATION}

Table 2

Cumulative Contextual Isolation among Long-Stay US Nursing Home Residents in 2016 with Alzheimer's Disease and Related Dementias and Reported Importance of Group Activity Participation, Stratified by Social Characteristic $(n=335,421)$

\begin{tabular}{|c|c|c|c|}
\hline \multirow[t]{3}{*}{ Social Characteristic } & \multicolumn{3}{|c|}{ Cumulative Contextual Isolation } \\
\hline & None & On Any One Characteristic & On Two or More Characteristics \\
\hline & & Percentage* & \\
\hline Total population & 55.5 & 30.7 & 13.7 \\
\hline Male & 45.7 & 34.4 & 19.9 \\
\hline Female & 59.6 & 29.2 & 11.2 \\
\hline Married & 46.6 & 34.6 & 18.8 \\
\hline Widowed & 63.1 & 27.6 & 9.3 \\
\hline Never Married, Divorced or Separated & 48.0 & 33.7 & 18.3 \\
\hline Young (age 50-64 years) & 28.4 & 35.9 & 35.7 \\
\hline $65-74$ years & 46.6 & 34.3 & 19.1 \\
\hline $75-84$ years & 55.0 & 31.2 & 13.9 \\
\hline $85-94$ years & 61.7 & 28.4 & 9.9 \\
\hline 95 years and older & 59.2 & 31.7 & 9.2 \\
\hline Hispanic, of any race(s) & 29.8 & 34.1 & 36.1 \\
\hline \multicolumn{4}{|l|}{ Not Hispanic and } \\
\hline White only & 61.0 & 30.0 & 10.0 \\
\hline Black only & 40.5 & 37.9 & 21.6 \\
\hline American Indian / Alaska Native only & 18.6 & 46.4 & 35.0 \\
\hline Asian only & 34.0 & 33.4 & 32.5 \\
\hline Native Hawaiian or other Pacific Islander only & 14.6 & 40.7 & 44.7 \\
\hline Multiracial & 0.0 & 55.8 & 44.2 \\
\hline Staff needs translator & 29.3 & 30.0 & 40.7 \\
\hline Staff does not need translator & 57.1 & 30.8 & 12.1 \\
\hline Heavy-bodied (BMI 30-60 kg/m²) & 53.3 & 31.4 & 15.3 \\
\hline Not heavy-bodied (BMI $15-30 \mathrm{~kg} / \mathrm{m}^{2}$ ) & 56.4 & 30.5 & 13.2 \\
\hline Current tobacco use & 19.4 & 45.2 & 35.4 \\
\hline No current tobacco use & 57.2 & 30.1 & 12.8 \\
\hline Religious practices important & 58.0 & 29.7 & 12.3 \\
\hline Religious practices not important & 45.7 & 34.9 & 19.3 \\
\hline Music important & 55.9 & 30.5 & 13.6 \\
\hline Music not important & 52.5 & 32.6 & 14.9 \\
\hline Pets/animals important & 56.7 & 30.2 & 13.0 \\
\hline Pets/animals not important & 53.4 & 31.6 & 15.0 \\
\hline News/current events important & 56.5 & 30.3 & 13.2 \\
\hline News/current events not important & 53.1 & 31.9 & 15.1 \\
\hline Intellectual disability & 6.5 & 49.7 & 43.8 \\
\hline No intellectual disability & 56.5 & 30.4 & 13.2 \\
\hline Sensory impairment & 25.6 & 48.3 & 26.2 \\
\hline No sensory impairment & 61.5 & 27.2 & 11.2 \\
\hline Disfiguring condition & 7.8 & 37.1 & 55.1 \\
\hline No disfiguring condition & 60.4 & 30.1 & 9.5 \\
\hline Stroke & 16.8 & 38.1 & 45.1 \\
\hline No stroke & 60.3 & 29.8 & 9.9 \\
\hline Cancer & 2.7 & 56.4 & 41.0 \\
\hline No cancer & 58.3 & 29.4 & 12.3 \\
\hline HIV infection & 10.7 & 41.2 & 48.1 \\
\hline No HIV infection & 55.6 & 30.7 & 13.7 \\
\hline End of life care & 3.4 & 50.9 & 45.7 \\
\hline Not end of life care & 56.6 & 30.3 & 13.1 \\
\hline
\end{tabular}

*Percentages may not total $100 \%$ due to rounding. 
Table 3

Importance of Group Activity Participation in Relation to Contextual Isolation on the Basis of Individual Characteristics among Long-Stay Residents in 2016 with Alzheimer's Disease and Related Dementias and Reported Importance of Group Activity Participation

\begin{tabular}{|c|c|c|}
\hline \multirow[b]{2}{*}{ Social Characteristic } & \multicolumn{2}{|c|}{$\begin{array}{l}\text { Proportion of residents (or proxies) reporting that group activity participation is "very important", "somewhat } \\
\text { important", or "important, but can't do or no choice". }\end{array}$} \\
\hline & Not Contextually Isolated on this Characteristic & Contextually Isolated on this Characteristic \\
\hline Male & 73.2 & 74.9 \\
\hline Female & 81.3 & 80.7 \\
\hline Married & 76.7 & 77.5 \\
\hline Widowed & 80.6 & 80.1 \\
\hline Never Married, Divorced or Separated & 77.4 & 76.9 \\
\hline Young age (50-64 years) & 78.3 & 76.7 \\
\hline Hispanic, of any race(s) & 84.4 & 80.0 \\
\hline \multicolumn{3}{|l|}{ Not Hispanic and } \\
\hline White only & 78.2 & 79.3 \\
\hline Black only & 81.8 & 79.6 \\
\hline American Indian / Alaska Native only & 76.9 & 76.3 \\
\hline Asian only & 85.5 & 81.1 \\
\hline Native Hawaiian or other Pacific Islander only & 83.3 & 80.6 \\
\hline Multiracial & $-\mathrm{a}$ & 77.6 \\
\hline Staff needs translator & 86.0 & 80.6 \\
\hline Heavy-bodied (BMI 30-60 kg/m²) & 80.4 & 83.8 \\
\hline Current tobacco use & 78.0 & 75.6 \\
\hline No current tobacco use & 79.1 & $-\mathrm{a}$ \\
\hline Religious practices important & 85.0 & 74.1 \\
\hline Religious practices not important & 54.8 & 55.7 \\
\hline Music important & 82.7 & $-\mathrm{a}$ \\
\hline Pets/animals important & 83.9 & 84.3 \\
\hline News/current events important & 82.0 & 73.3 \\
\hline Intellectual disability & 83.6 & 81.8 \\
\hline Sensory impairment & 77.2 & 75.5 \\
\hline Disfiguring condition & 79.2 & 76.1 \\
\hline Stroke & 78.6 & 76.6 \\
\hline Cancer & 75.7 & 77.6 \\
\hline HIV infection & 88.2 & 82.9 \\
\hline End of life care & 71.9 & 72.6 \\
\hline
\end{tabular}

a. Proportions based on a numerator under 50 not reported to avoid imprecise estimates.

do not engage in religious practice did. Despite often large differences in the importance of group participation across strata, in most strata, residents who were contextually isolated on the basis of multiple characteristics were at least $5 \%$ less likely to report participation in group activities as important (in absolute terms). For example, among White residents, $80.8 \%$ of those who were not contextually isolated rated group activity participation as important, while $72.6 \%$ of those experiencing contextual isolation across multiple characteristics did.

Among 94,735 residents unable to complete the resident assessment of the importance of group activity participation, $63.6 \%$ of those not contextually isolated were observed by staff to have participated in group activities, while $58.7 \%$ of those contextually isolated on the basis of a single characteristic were observed participating in group activities, and $52.5 \%$ of residents contextually isolated on the basis of multiple characteristics were observed participating in group activities. These data, as well as stratum-specific data comparable to Table 4 can be found in Supplemental Table 7.

Supplemental Table 8 shows the proportion of residents considered contextually isolated when defined as sharing a nursing home with fewer than $10 \%$, and fewer than $15 \%$ of residents with the same social characteristic. By definition, fewer residents are considered contextually isolated when using a lower threshold for defining contextual isolation. Supplemental Table 9, in turn, shows the proportion of residents considered contextually isolated with respect to any single characteristic, and with respect to multiple characteristics, when the threshold for contextual isolation is lowered to $10 \%$. Following the results in Supplemental Table 8, these proportions are lower than those shown in Table 3. 


\section{CONTEXTUAL SOCIAL ISOLATION}

Table 4

Importance of Group Activity Participation by Cumulative Contextual Isolation among Long-Stay Residents in 2016 with Alzheimer's Disease and Related Dementias Living in a Nursing Home and Reported Importance of Group Activity Participation, Stratified by Social Characteristic

\begin{tabular}{|c|c|c|c|}
\hline & \multicolumn{3}{|c|}{$\begin{array}{l}\text { Proportion of residents (or proxies) reporting that group activity participation is "very important", "somewhat important", } \\
\text { or "important, but can't do or no choice". }\end{array}$} \\
\hline & $\begin{array}{c}\text { Not Contextually Isolated on Any } \\
\text { Characteristics }\end{array}$ & $\begin{array}{l}\text { Contextually Isolated on One } \\
\text { Characteristic }\end{array}$ & $\begin{array}{l}\text { Contextually Isolated on Multiple } \\
\text { Characteristics }\end{array}$ \\
\hline Total & 80.6 & 77.6 & 75.2 \\
\hline Male & 74.3 & 72.9 & 71.3 \\
\hline Female & 82.6 & 79.9 & 78.1 \\
\hline Married & 78.2 & 76.5 & 74.2 \\
\hline Widowed & 82.1 & 78.6 & 76.4 \\
\hline Divorced, Separated, or Never Married & 78.7 & 77.0 & 74.8 \\
\hline Young (age 50-64 years) & 78.6 & 77.9 & 77.0 \\
\hline $65-74$ years & 78.7 & 76.2 & 73.6 \\
\hline $75-84$ years & 79.6 & 77.0 & 74.3 \\
\hline $85-94$ years & 81.5 & 78.4 & 75.9 \\
\hline 95 years and older & 82.0 & 78.0 & 75.9 \\
\hline Hispanic of any race(s) & 86.7 & 82.0 & 79.6 \\
\hline \multicolumn{4}{|l|}{ Not Hispanic and } \\
\hline White only & 80.8 & 76.3 & 72.6 \\
\hline Black only & 83.6 & 80.6 & 77.8 \\
\hline American Indian / Alaska Native only & 77.2 & 79.9 & 71.7 \\
\hline Asian only & 85.7 & 84.7 & 79.9 \\
\hline Native Hawaiian or other Pacific Islander only & 82.5 & 81.9 & 80.2 \\
\hline Multiracial & $-\mathrm{a}$ & 86.6 & $-\mathrm{a}$ \\
\hline Translation services needed & 87.8 & 84.6 & 79.8 \\
\hline Translation services not needed & 80.4 & 77.2 & 74.3 \\
\hline Heavy-bodied (BMI 30-60kg/m²) & 81.7 & 79.9 & 78.1 \\
\hline Not heavy-bodied (BMI $15-30 \mathrm{~kg} / \mathrm{m}^{2}$ ) & 80.3 & 76.8 & 74.0 \\
\hline Current tobacco use & 77.9 & 77.5 & 74.4 \\
\hline No current tobacco use & 80.7 & 77.6 & 75.3 \\
\hline Religious Practice Important & 85.6 & 84.5 & 83.5 \\
\hline Religious Practice not Important & 55.7 & 54.4 & 54.1 \\
\hline Music Important & 84.1 & 81.6 & 79.3 \\
\hline Music not Important & 49.7 & 46.6 & 44.1 \\
\hline Pets/Animals Important & 84.9 & 83.0 & 81.2 \\
\hline Pets/animals not Important & 72.5 & 68.4 & 65.9 \\
\hline News/Current Events Important & 83.3 & 81.0 & 79.1 \\
\hline News/Current Events not Important & 73.1 & 69.2 & 66.2 \\
\hline Intellectual Disability & 83.9 & 82.8 & 80.9 \\
\hline No Intellectual Disability & 80.6 & 77.5 & 74.8 \\
\hline Sensory Impairment & 78.4 & 76.6 & 73.3 \\
\hline No Sensory Impairment & 80.8 & 78.0 & 76.1 \\
\hline Disfiguring Condition & 81.0 & 77.7 & 75.2 \\
\hline No Disfiguring Condition & 80.6 & 77.6 & 75.2 \\
\hline Stroke & 80.9 & 78.3 & 75.3 \\
\hline No Stroke & 80.6 & 77.5 & 75.1 \\
\hline Cancer & 79.0 & 79.2 & 75.2 \\
\hline No Cancer & 80.6 & 77.5 & 75.2 \\
\hline HIV & 88.8 & 83.1 & 83.8 \\
\hline No HIV & 80.6 & 77.6 & 75.1 \\
\hline End-of-Life Care & 71.9 & 73.8 & 71.1 \\
\hline Not End-of-Life Care & 80.6 & 77.8 & 75.5 \\
\hline
\end{tabular}




\section{THE JOURNAL OF NURSING HOME RESEARCH SCIENCESC}

\section{Discussion}

The concept of contextual isolation encourages understanding the potential for isolation of each resident in context, rather than as the sum of individual risk factors, and reframes efforts to address isolation and loneliness from an individualized process of risk assessment and intervention to one focused on systematic and relational approaches that validate-even cherish-the diverse views, experiences, and strengths that residents have to offer.

These analyses demonstrate that not only is contextual isolation in nursing home residents with ADRD a common experience, but that it is related to diminished participation in group activities. Residents sharing a socially salient characteristic often place less importance on group activity participation when they are in settings where they are contextually isolated with respect to multiple characteristics. One plausible interpretation of these findings is that residents with ADRD who live in a context where a socially salient characteristic puts them in a minority have greater difficulty developing a sense of solidarity and inclusion. Alternately, these residents may be at risk of exclusion or ostracism from the larger population of residents, diminishing their interest in participating in group activities. The finding that staff observation of participation in group activities often showed an even stronger association with contextual isolation than the expression of resident interest bolsters this interpretation.

Being contextually isolated is far from determinative of group activity participation. The majority of residents we examined either rated participation in group activities as important or had staff observe group activity participation. Taking the findings based on importance of group participation and observed group activity participation reported by staff together points to the need for nuance in interpreting this overall narrative. For instance, both residents who live in a setting where staff need translation services to communicate with them and those who don't demonstrated a stronger gradient from no contextual isolation to multiple contextual isolation than the population as a whole. This may suggest there is negative confounding when looking at the whole population. Additionally, some of the groups who were least likely to experience contextual isolation nonetheless saw a notable $(>5 \%)$ decrease in placing high importance on group activity participation when they were contextually isolated. These included non-Hispanic White residents, female residents, and those whose weight for height was lower than $30 \mathrm{~kg} / \mathrm{m}^{2}$. These findings may suggest that residents coming from a socially dominant position in the larger society may be more likely to avoid group activities when confronted with the possibility of being in the minority, while residents with a lifetime of experience negotiating as a minority in one way or another are better prepared to handle group interactions in a diverse setting.

Alternate explanations include the possibility that residents in a minority position may feel some degree of exclusion in dyadic interactions, and thus express an even greater preference for group activities, which may involve more oversight and structure provided by staff to facilitate healthy and supportive interactions. Qualitative analyses of the individual, dyadic, small, and large group interactions of residents with ADRD in nursing home settings will be required to assess these potential explanations, as well as to add dimensionality to the quantitative findings of this analysis.

\section{Strengths and Limitations}

This analysis was performed on a census of residents in 2016 living in US nursing homes for at least one year with ADRD, aside from exclusions for missing data. The MDS item assessing the importance the resident places on participation in group activities is not, to our knowledge, incorporated into any quality indicators, nor does it serve as the basis for determining differences in reimbursement rates. As a result, it may be perceived as a low salience item and be filled in without great attention to detail. Direct assessment of the importance a resident places on participation in group activities is not conducted when a) the resident is judged unable to communicate and a family member is not present to serve as a proxy, or b) previous items designed to assess resident preferences and activity patterns were not answered. It is plausible that staff may be more likely to code a resident as non-responsive or non-communicative in ways that are causally related to the very contextual isolation these residents face. Although the inclusion of the resident's voice in the MDS assessment instrument is a welcome improvement over previous assessment techniques (28), in this case, the resident's expression of the importance of group activity participation may not closely reflect the degree to which contextually isolated residents are invited and welcomed to participate fully and authentically in these activities.

Our measure of contextual isolation is based on measures incorporated into MDS 3.0 that have sufficiently low missingness to be reliably incorporated into these measures for a wide range of populations. There are many other dimensions of identity and socialization that may have a large influence on contextual isolation in the nursing home setting, including prior occupation and social class $(13,23)$, sexual and gender minority status $(2,11,26)$, and even musical preferences (18). Thus, our measure of contextual isolation is incomplete, and in addition, does not reflect the potential for greater degrees of isolation associated with different socially salient characteristics.

Our main hypothesis that residents experiencing contextual isolation would be less fully included in group activities ignores several important additional contextual factors that may have a large influence on the experience of contextually isolated residents. For instance, contextual isolation in a nursing home dominated by a single majority group is likely to be a distinct experience from being contextually isolated in a diverse setting where multiple groups interact frequently, although these scenarios are treated interchangeably in our formulation. Similarly, contextual isolation in relation to other 


\section{CONTEXTUAL SOCIAL ISOLATION}

residents may not reflect isolation when staff are incorporated into the picture. For example, a Filipina resident who is in a relatively small minority with respect to other residents may feel common bonds and solidarity with Filipino/a staff that could compensate for what might be an isolating experience when only other residents are considered. Furthermore, in a nursing home culture where diverse experiences and backgrounds are cherished and revered, rather than serving as the basis for exclusion (as our hypothesis implicitly assumes), the experience of being contextually isolated may have little to no bearing on the experience of feeling isolated or lonely as an individual resident. Likewise, staff engagement impacts resident participation in group activities (19), suggesting a large role for staff in proactively addressing contextual isolation by being solicitous of residents who might otherwise be at risk of social isolation (3). In addition, observations in Veterans Affairs nursing homes have demonstrated that residents have much more frequent interactions with staff and the environment than with other residents (22), potentially limiting the proposed mechanism we explore here that group activity participation is inflected by social interactions based on resident composition in the nursing home setting.

\section{Conclusion}

Residents with ADRD who are contextually isolated, that is, who share socially salient characteristic(s) with fewer than $20 \%$ of their co-residents, often put less importance on participation in group activities than residents who are not contextually isolated. Contextually isolated residents are also less likely to be observed participating in group activities by staff. This overall trend is somewhat more pronounced in groups of residents sharing racial/ethnic identities, in nursing homes where staff require translation services to communicate with them, residents living with HIV, and residents with lower weight for height. Nursing homes should consider, at the level of a residential community, means to encourage group activities that incorporate the full richness and diversity of their residential population.

Acknowledgements: We thank Lynn Botelho for her insights into social interactions in nursing homes, seven anonymous experts in nursing home care for insights on further refining the concept of contextual isolation, and Divya Shridharmurthy for coding the nursing expert survey into RedCap.

Funding: This work was funded by the National Institutes of Health (NR016977, TR001454, and AG071692 to Dr. Lapane). The sponsors had no role in the design and conduct of the study; in the collection, analysis, and interpretation of data; in the preparation of the manuscript; or in the review or approval of the manuscript.

Declaration of Interest: Bill M. Jesdale has no conflicts of interest to declare; Carol A. Bova has no conflicts of interest to declare; Attah K. Mbrah has no conflicts of interest to declare; Kate L. Lapane has no conflicts of interest to declare.

Ethical Approval for Study: This study was approved by the University of Massachusetts Institutional Review Board.

\section{References}

1. Bailey, E. M., Stevens, A. B., LaRocca, M. A., \& Scogin, F. 2016. A Randomized Controlled Trial of a Therapeutic Intervention for Nursing Home Residents With Dementia and Depressive Symptoms. 2016;1552-4523 (Electronic).
2. Bloemen, E. M., Rosen, T., LoFaso, V. M., et al. (2019). Lesbian, Gay, Bisexual, and Transgender Older Adults' Experiences With Elder Abuse and Neglect. 2019;15325415 (Electronic)

3. Buron, B., \& Killian, T. 2014. Promoting Personhood in Men in Nursing Homes: The Role of Activity Directors. Annals of Long-Term Care: Clinical Care and Aging. 2014;22, 28-33.

4. Centers for Medicare \& Medicaid Services. MDS 3.0 RAI Manual. Retrieved 2020 Jun 26 from https://www.cms.gov/Medicare/Quality-Initiatives-Patient-AssessmentInstruments/NursingHomeQualityInits/MDS30RAIManual

5. Cohen-Mansfield, J. The impact of group activities and their content on persons with dementia attending them. Alzheimers Res Ther, 2018, Apr 5 10(1), 37. https://doi. org/10.1186/s13195-018-0357-z

6. Cohen-Mansfield, J., Marx, M., Dakheel-Ali, M., Regier, N., Thein, K., \& Freedman, L. Can agitated behavior of nursing home residents with dementia be prevented with the use of standardized stimuli? 2010;1532-5415 (Electronic).

7. Cohen-Mansfield, J., Marx, M. S., Regier, N. G., \& Dakheel-Ali, M. The impact of personal characteristics on engagement in nursing home residents with dementia. Int J Geriatr Psychiatry, 2009, Jul 24(7), 755-763. https://doi.org/10.1002/gps.2192

8. Cohen-Mansfield, J., Thein, K., Dakheel-Ali, M., \& Marx, M. S. Engaging nursing home residents with dementia in activities: the effects of modeling, presentation order, time of day, and setting characteristics. 2010;1364-6915 (Electronic).

9. de Jong-Gierveld, J. A review of loneliness: Concepts and definitions, determinants and consequences. Reviews in Clinical Gerontology(8), 1998;73-80. https://doi.org/ https://doi.org/10.1017/S0959259898008090

10. Elovainio, M., Hakulinen, C., Pulkki-Råback, et al. Contribution of risk factors to excess mortality in isolated and lonely individuals: an analysis of data from the UK Biobank cohort study. 2017;2468-2667 (Print).

11. Fredriksen-Goldsen, K. I., Jen, S., Bryan, A. E. B., \& Goldsen, J. Cognitive Impairment, Alzheimer's Disease, and Other Dementias in the Lives of Lesbian, Gay, Bisexual and Transgender (LGBT) Older Adults and Their Caregivers: Needs and Competencies. 2016;1552-4523 (Electronic).

12. Grenade, L., \& Boldy, D. Social isolation and loneliness among older people: issues and future challenges in community and residential settings. 2008;0156-5788 (Print).

13. Haller, E., Binder, R., \& McNiel, D. E. Violence in geriatric patients with dementia 1989;0091-634X (Print).

14. Heid, A. R., Bangerter, L. R., Abbott, K. M., \& Van Haitsma, K. Do Family Proxies Get It Right? Concordance in Reports of Nursing Home Residents' Everyday Preferences. J Appl Gerontol, 2017, Jun 36(6), 667-691. https://doi. org/10.1177/0733464815581485. Epub 2015 Apr 28

15. Holt-Lunstad, J., Smith, T. B., Baker, M., Harris, T., \& Stephenson, D. Loneliness and social isolation as risk factors for mortality: a meta-analytic review. 2015;17456924 (Electronic).

16. House, J. S., Landis, K., \& Umberson, D. Social relationships and health. 1988;00368075 (Print).

17. Housen, P., Shannon, G., Simon, B., et al. Why not just ask the resident? 2009;00989134 (Print)

18. Jonas, J. L. Preferences of elderly music listeners residing in nursing homes for art music, traditional jazz, popular music of today, and country music. 1991;0022-2917 (Print).

19. Meeks, S., \& Looney, S. W. . Depressed nursing home residents' activity participation and affect as a function of staff engagement. Behav Ther, 2011, Mar;42(1),22-29. https://doi.org/10.1016/j.beth.2010.01.004. Epub 2010 Sep 16.

20. Nursing Home Facilities: Programs and Services: Table 20. Retrieved 2020 June 28 from https://www.cdc.gov/nchs/data/nnhsd/nursinghomefacilities2006.pdf\#11

21. Paque, K., Bastiaens, H., Van Bogaert, P., \& Dilles, T. Living in a nursing home: a phenomenological study exploring residents' loneliness and other feelings. Scand J Caring Sci, 2018;32(1471-6712 (Electronic)), 1477-1484. https://doi.org/ doi: $10.1111 /$ scs.12599

22. Pineles, L., Perencevich, E. N., Roghmann, M. C., et al. . Frequency of nursing home resident contact with staff, other residents, and the environment outside resident rooms. Infect Control Hosp Epidemiol, 2019, Jul;40(7), 815-816. https://doi. org/10.1017/ice.2019.117. Epub 2019 May 20.

23. Retsinas, J., \& Garrity, P. Nursing home friendships. The Gerontologist, 1985;25(4), 376-381. https://doi.org/10.1093/geront/25.4.376

24. Savikko, N., Routasalo, P., Tilvis, R., Strandberg, T., \& Pitkälä, K. H. Predictors and subjective causes of loneliness in an aged population. 2005;0167-4943 (Print).

25. Smit, D., de Lange, J., Willemse, B., \& Pot, A. M. Predictors of activity involvement in dementia care homes: a cross-sectional study. 2017;1471-2318 (Electronic)).

26. Sussman, T., Brotman, S., MacIntosh, H., et al. Supporting Lesbian, Gay, Bisexual, \& Transgender Inclusivity in Long-Term Care Homes: A Canadian Perspective. 2018;1710-1107 (Electronic)

27. Taylor, C., Greenlund, S., McGuire, L., Lu, H., \& Croft, J. B. Deaths from Alzheimer's Disease - United States, 1999-2014. 2017;1545-861X (Electronic).

28. Thomas, K., Wysocki, A., Intrator, O., \& Mor, V. Finding Gertrude: The resident's voice in Minimum Data Set 3.0. J Am Med Dir Assoc, 2014;15(1538-9375 (Electronic)), 802-806

29. Zissimopoulos, J., Crimmins, E., \& St Clair, P. The Value of Delaying Alzheimer's Disease Onset. (2014;2194-6191 (Print). 